Conde, M. Á., Fernández-Llamas, C., Rodríguez-Lera, F. J., Rodríguez-Sedano, F. J., Matellán-Olivera, V., \& García-Peñalvo, F. J. (2016). Analysing the attitude of students towards robots when lectured on programming by robotic or human teachers. In F. J. GarcíaPeñalvo (Ed.), Proceedings of the Fourth International Conference on Technological Ecosystems for Enhancing Multiculturality

(TEEM'16) (Salamanca, Spain, November 2-4, 2016) (pp. 59-65). New York, NY, USA: ACM. doi: 10.1145/3012430.3012497

\title{
Analysing the attitude of students towards robots when lectured on programming by robotic or human teachers
}

\author{
Miguel Á. Conde, Camino Fernández, Francisco J. Rodríguez-Lera, Francisco J. Rodríguez-Sedano, \\ Vicente Matellán \\ Grupo de Robótica. \\ Depto. Ingenierías Mecánica, Informática y Aeroespacial \\ Escuela de Ingenierías Industrial e Informática \\ Universidad de León. 24008-León (Spain) \\ (+34) 987-291-000 \\ \{mcong, cferll, frods, frodl, vmato\}@unileon.es
}

Francisco J. García-Peñalvo

Grupo de Investigación en Interacción y eLearning

Facultad de Ciencias. Plaza de los Caídos s/n

Universidad de Salamanca

37008 Salamanca (Spain)

(+34) 923-294-500 (ext. 1302)

fgarcia@usal.es

\begin{abstract}
The study presented in this paper explored the acceptance of robots as teachers for a group of K-12 students. These students attended a programming session designed to applied computational principles in different fields. We have analyzed how this acceptance varies with age, and also if their opinion changes if they were exposed to a real robot teacher or not. To this end, participants $(\mathrm{N}=210)$ were divided in two groups, one was lectured by a teacher and the other one by a Baxter robot. We used the Negative Attitudes towards Robots Scale and the Robot Anxiety Scale questionnaires to evaluate students perception. Statistical analysis of the answers to these questionnaires is discussed in the paper, both taking into account the whole groups and another considering three subgroups based on age. Main conclusion of the study is that the use of the robot is relevant in the perception of the students about robots, but also that age is significant in the perception of robots as potential teachers.
\end{abstract}

CCS Concepts

- Applied Computing $\rightarrow$ Education $\rightarrow$ Computer Assisted instruction • Human-centered computing $\rightarrow$ Laboratory experiments; - Computer systems organization $\rightarrow$ Embedded and cyber-physical systems $\rightarrow$ Robotics

\section{Keywords}

Educational Robotics; Human Robot Interaction; Social Robotics; Learning.

\section{INTRODUCTION}

There are many proposals to encourage computational thinking [1][2] in K-12 curricula. Many projects have explored different programming environments, developed tools, and generated material to teach computing to K-12 students. For instance, some of the authors of these work are involved in the Taccle3 Coding project[3] were a website of ideas and resources is being develop together with inservice training courses and other staff development events.

Several other approaches have taken, as simulation, game design, or even robots. Robots[4] in particular have been extensively proposed as learning tools.

However, there is a lack of empirical evidence on the educational effectiveness of the use of robots [5]. There many issues that need to be analyzed in order to prescribe them for a particular learning environment.

Researchers have suggested that individual differences in terms of underlying personality or gender may play a significant role on how robots are perceived and responded to by potential users [5]. In the same way, they have also made experiments that evaluate the differences when considering previous experience with computers and robots [7].

However, other authors [8] have shown that pre-existing attitudes towards robots are difficult to extrapolate purely from demographics or from previous experiences of technology use. 
Conde, M. Á., Fernández-Llamas, C., Rodríguez-Lera, F. J., Rodríguez-Sedano, F. J., Matellán-Olivera, V., \& García-Peñalvo, F. J. (2016). Analysing the attitude of students towards robots when lectured on programming by robotic or human teachers. In F. J. GarcíaPeñalvo (Ed.), Proceedings of the Fourth International Conference on Technological Ecosystems for Enhancing Multiculturality (TEEM'16) (Salamanca, Spain, November 2-4, 2016) (pp. 59-65). New York, NY, USA: ACM. doi: 10.1145/3012430.3012497

Other aspect to take into account is the context where the evaluation has taken place. For instance, many of the experiments regarding the influence of gender or previous experience with technology on the attitude towards robots [9] has been made in the context of robotic assistants.

We are interested on exploring the relationships between age and previous experience using IT-technology for the acceptance of robots as teachers.

In particular, this work analyses the performance of a group of K-12 students when the same classes were taught by a robot or by a human teacher. The whole experiment was designed to evaluate the performance of the students when applying the computational concepts learnt in a programming environment to other areas. In this paper we will focus in the attitude towards robots.

Negative Attitudes towards Robots Scale (NARS) scale [10] has been proposed to evaluate these differences in different experiments. Nomura et al. [11] also studied the relationship between the NARS scale and the Robot Anxiety Scale (RAS) that we have used in this paper.

The rest of the paper is organized as follows. Second section formulates the hypothesis analyzed in this paper. Third section describes in detail the experiment designed to evaluate these hypotheses. Section four presents the statistical analysis of the data gathered, which are discussed in the fifth section. Finally, section six summarizes the conclusions obtained in this research and the further work envisioned.

\section{AIMS OF THE RESEARCH}

Fascination for technology presents robots everywhere in a near future. But, are final users ready for them? We are interested in the role that robots could play in teaching environments, in particular when they are used for teaching computational principles and in the

In order to evaluate students' attitude towards robots we designed an experiment where the same computational concepts are taught by a robot and by a human teacher to two different groups of students ranging from 6 to 16 years of age.

Our main goal was to analyze the differences, if any, between the two environments regarding learning. An important issue to be taken into account was the attitude of students towards robots, and if gender, age or previous knowledge affects their perception.

With all this in mind, the main issues to evaluate in this work were:

1) Whether a robotic teacher does increase the NARS and RAS evaluation or not.

2) Which factors affects students' perception towards robots.

3) Which is the relationship between these factors.

\section{EXPERIMENTAL SETUP}

Experimental setup has an important role to analyze the attitude towards robots. In this particular case we can contrast pre-existing opinions about robots versus new opinions after interacting with real robots.

The experiment was organized in two different scenarios; one with a human teacher and another with a robot teacher. The same script was used in both. First, teachers gave a brief lecture using the same outline and the same slides. Then, teachers explained the exercises that students should carry out. Last, students would make the exercises and fill a and a RAS questionnaire.

NARS has been used in similar analysis of robotic systems for education as in Nomura [11]. It measures the psychological states reflecting opinions that people used to have about robots. It is a questionnaire based on a Likert scale composed by fourteen statements.

The NARS questionnaire presents three subscales (number of questions):

- $\quad$ Negative Attitude toward Interaction with Robots (6)

- Negative Attitude toward the Social Influence of Robots (5)

- $\quad$ Negative Attitude towards Emotional Interactions with Robots (3).

The RAS questionnaire presents also three subscales with a bounded number of questions:

- $\quad$ Negative Attitude toward Communication with Robots (3)

- Negative Attitude toward Robots' Behavior (4)

- Negative Attitude toward Robots' Discourse (4).

The Likert approach in NARS offers a five-point scale from 1 (Strongly disagree) to 5 (Strongly agree). If the final result shows a high score it means more negative attitude toward robots.

\subsection{Description of the experiment}

The human teacher was a programming teacher with more than ten years of experience lecturing in introductory programming courses at university level.

The robot teacher was a Baxter robot. Baxter is an industrial robot manufactured by Rethink Robotics that consists of two seven degree-offreedom arms attached to a torso topped by a head made up by a display. Baxter has several sensors: one camera on each griper along with an infrared sensor range $(4-40 \mathrm{~cm})$, one camera on top of the robot display, range finding sensors integrated on top of the robot's head, and several perceptive sensors. 
Conde, M. Á., Fernández-Llamas, C., Rodríguez-Lera, F. J., Rodríguez-Sedano, F. J., Matellán-Olivera, V., \& García-Peñalvo, F. J. (2016). Analysing the attitude of students towards robots when lectured on programming by robotic or human teachers. In F. J. GarcíaPeñalvo (Ed.), Proceedings of the Fourth International Conference on Technological Ecosystems for Enhancing Multiculturality

(TEEM'16) (Salamanca, Spain, November 2-4, 2016) (pp. 59-65). New York, NY, USA: ACM. doi: 10.1145/3012430.3012497

In order to use Baxter as a teacher, voice capabilities were added using Festival ${ }^{1}$. Along with the voice, the face of the robot also played an important role. A friendly face with moving eyes was used in order to improve human-robot interaction. Figure 1 shows Baxter during a lecture.

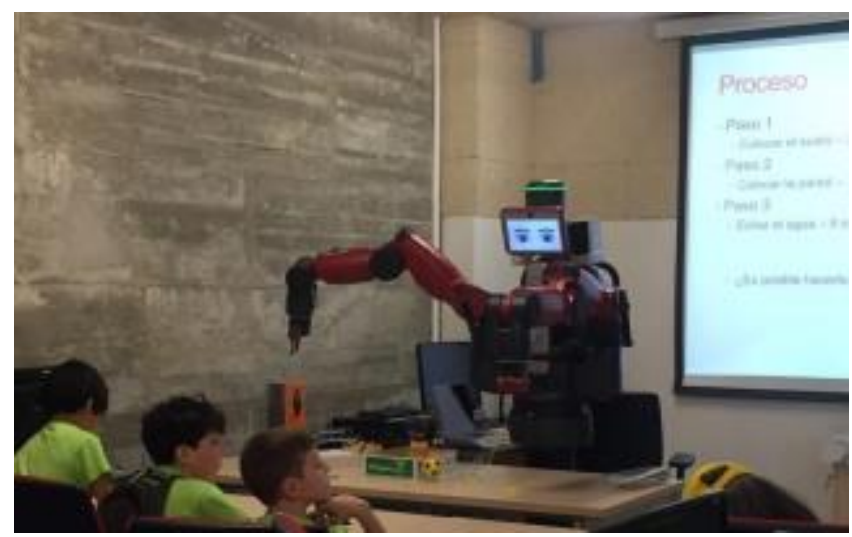

Figure 1. Baxter robot lecturing

The experiment involved a group of 210 students aged between 6 and 16 years. Each group was to be randomly split into two. One group would be assigned to the human teacher class and the other one to Baxter class. The students were in a summer tech camp. Besides, students could have had some other programming courses at school or somewhere else. In order to have some information about this fact, a question was included in the initial questionnaire together with their age, sex and school.

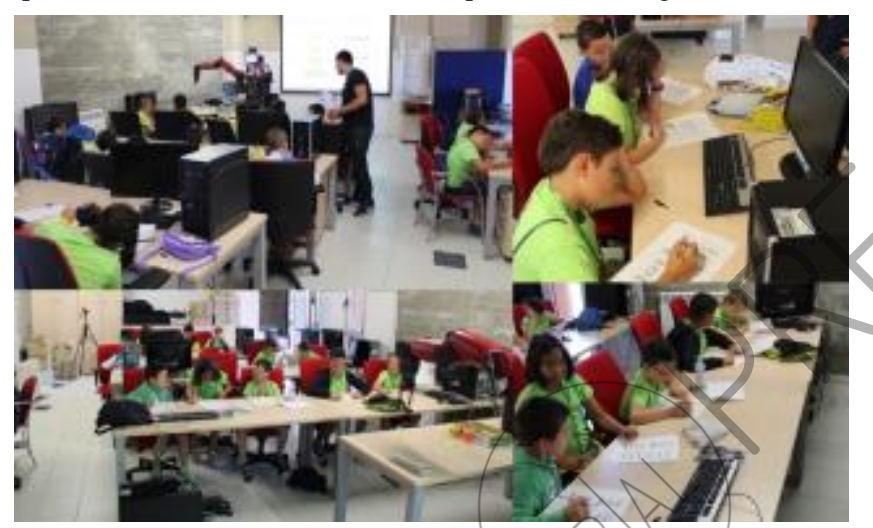

Figure 2. Students working during the experiment

The lecture started with both the human teacher and Baxter following the same script for explaining two basic programming concepts: Repetition and condition. The human teacher would explain these concepts with the support of the same slides used by Baxter. Baxter would additionally show these two concepts with a demo.

For showing the repetition, Baxter takes a ball from a ramp and drops it on a box repeatedly, weather there is a ball or not. For showing the condition, Baxter takes a ball from a spot only if there is a ball on that spot. At the end of the explanation, both teachers would explain the exercises to be performed by students.

For practicing both repetition and condition, a practical exercise was proposed. The exercise consisted of building a swimming pool in a Minecraft world. Minecraft was chosen because it is a very popular game among children, it has clearly recognizable graphics and uses different types of blocks. Problem had to be solved using Scratch programming environment because they have been learning about it in the Summer Camp where they were enrolled. However, exercises were made on paper to avoid problems with the use of the computers, or using the Scratch editor (see Figure 2).

Students should use a 25 times repetition block to place the floor. In the second step they should use a 16 repetition block to place the wall. And in the third step they should use a 9 repetition block to place the water. Figure 3 shows the response sheet designed for students to perform the exercise.

The goal of the experiment was to check if students were able to apply the computational principles taught by Baxter or the human teacher to a different domain (Minecraft).

\footnotetext{
${ }^{1}$ http://www.cstr.ed.ac.uk/projects/festival
} 
Conde, M. Á., Fernández-Llamas, C., Rodríguez-Lera, F. J., Rodríguez-Sedano, F. J., Matellán-Olivera, V., \& García-Peñalvo, F. J. (2016). Analysing the attitude of students towards robots when lectured on programming by robotic or human teachers. In F. J. GarcíaPeñalvo (Ed.), Proceedings of the Fourth International Conference on Technological Ecosystems for Enhancing Multiculturality

(TEEM'16) (Salamanca, Spain, November 2-4, 2016) (pp. 59-65). New York, NY, USA: ACM. doi: 10.1145/3012430.3012497

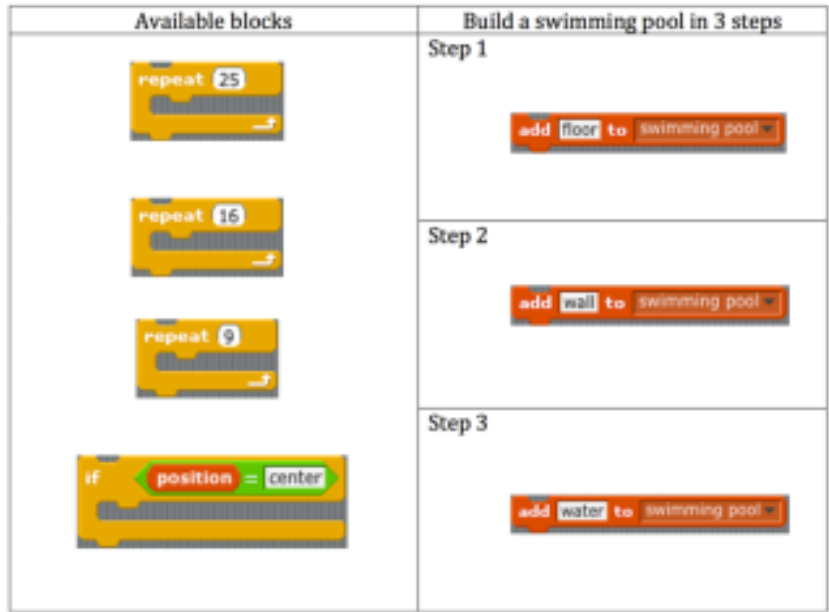

Figure 3: Response sheet for the first part of the exercise

In order to do so, in the second part of the exercise, students were asked to solve the problem only in two steps. The first one should be identical to the first part, that is, they should use a 25 repetition block for the floor. But in the second step, they only could use a 25 repetition block to cover all the surface of the floor for placing the wall (see Figur3 4). This means that they have to nest a condition block to place water in the center position of the swimming pool. Nesting conditions in loops was not explicitly taught to the students.

\subsection{Methodology}

Each group of students was escorted by their monitor at the summer camp. During the experiment, besides the human teacher or Baxter, there was at least another person from the organization for assisting the whole process as well as the monitor.

Monitors were in charge of providing students with the exercise sheets, ball-pens, and anything they would need. They would also answer questions about the exercises and the questionnaires.

The exercise had two different parts. In the first part, students were asked to solve the problem in three steps. In the first one they should use a 25 times repetition block to place the floor.

In the second step they should use a 16 repetition block to place the wall. And in the third step they should use a 9 repetition block to place the water.

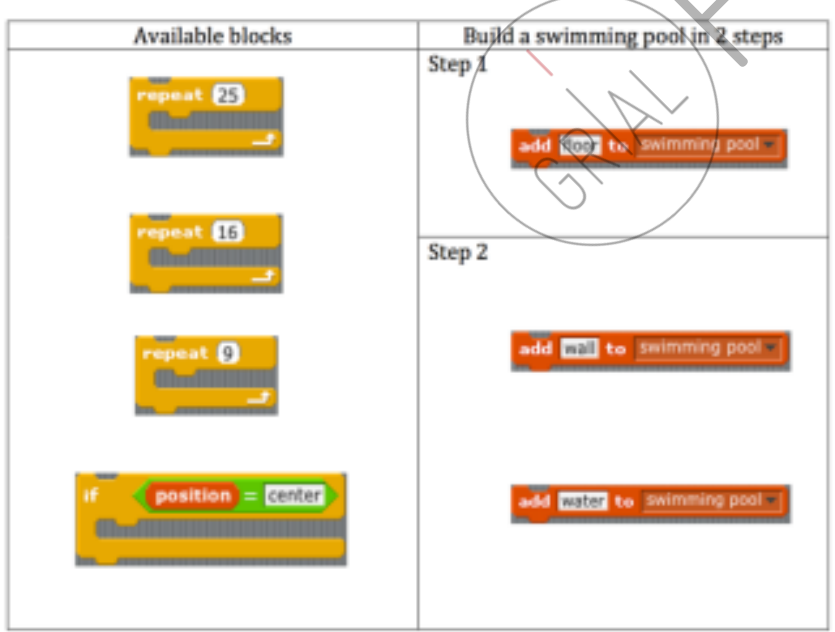

Figure 4: Response sheet for the second part.

The explanation of the concepts lasted for fifteen to twenty minutes. After that, students had around the same amount of time to perform both the exercises and the NARS questionnaire.

The experiment was repeated three times along three consecutive weeks with different groups of students. 
Conde, M. Á., Fernández-Llamas, C., Rodríguez-Lera, F. J., Rodríguez-Sedano, F. J., Matellán-Olivera, V., \& García-Peñalvo, F. J. (2016). Analysing the attitude of students towards robots when lectured on programming by robotic or human teachers. In F. J. GarcíaPeñalvo (Ed.), Proceedings of the Fourth International Conference on Technological Ecosystems for Enhancing Multiculturality (TEEM'16) (Salamanca, Spain, November 2-4, 2016) (pp. 59-65). New York, NY, USA: ACM. doi: 10.1145/3012430.3012497

\section{DATA ANALYSIS}

The total number of students that participated in the experiment was 210,114 of the them had Baxter as a teacher and the 96 remaining had a human teacher. Students' age range was from 6 to 16. Experiment results have been analyzed as a whole and also by groups. Groups division were made according to Spanish Educational Law: Primary1 from 6 to 9 years old, Primary2 from 10 to 13 and Secondary from 13 to 17 years old.

\subsection{Frequency Analysis}

A summary of the frequency answers to NARS que can be seen in Table 1 and in Table 2 for RAS. These tables show the distributions of the different answers for each item organized by groups defined by age and for the whole population of the experiment. It is possible to see differences in the attitudes towards robots between the students' answers depending on the age group they belong to, and it would be also interesting to see if there is any difference when the student has a human teacher during the experience and when only Baxter is used. That is, we aim to check the posed hypothesis by employing the data gathered during the experiment. This information is quantitative so different statistical techniques were applied.

We have made different groups of the students that interact with the human teacher and the robot in order to compare the results of each of the items of NARS and RAS questionnaires. Later on a comparison taking into account age ranges is done.

To carry out this comparison average results of students were studied. These average comparisons require first to study homogeneity by applying Levene test, if the significance is greater than 0.05 and the sample size is greater than 30 a Student T test could be applied. On the contrary a non-parametric test would be chosen. This procedure was applied per each item, some items required non-parametric test and other do not.

Table 1. - Frequency distribution for NARS Items (NS= Not Sure; NA= Not Answering)

\begin{tabular}{|c|c|c|c|c|c|c|c|c|c|c|c|c|c|c|c|c|}
\hline Item & \multicolumn{4}{|c|}{ ALL STUDENTS } & \multicolumn{4}{|c|}{ PRIMARY 1} & \multicolumn{4}{|c|}{ PRIMARY 2} & \multicolumn{4}{|c|}{ SECONDARY } \\
\hline & No & Yes & NS & NK/NA & No & Yes & NS & NK/NA & No & Yes & NS & NK/NA & No & Yes & NS & NK/NA \\
\hline I1 & 24.8 & 50.0 & 22.9 & 2.4 & 31.3 & 46.3 & 20.9 & 1.5 & 22.4 & 58.2 & 19.4 & 0 & 21.1 & 46.1 & 27.6 & 5.3 \\
\hline $\mathrm{I} 2$ & 53.8 & 29.5 & 9.0 & 7.7 & 49.3 & 29.9 & 17.9 & 3 & 56.7 & 29.9 & 9.0 & 4.5 & 55.3 & 28.9 & 1.3 & 14.4 \\
\hline $\mathrm{I} 3$ & 56.7 & 21.0 & 21.4 & 1.0 & 56.7 & 26.9 & 16.4 & 0 & 55.2 & 22.4 & 20.9 & 1.5 & 57.9 & 14.5 & 26.3 & 1.3 \\
\hline I4 & 72.4 & 9.0 & 15.7 & 2.8 & 89.6 & 6.0 & & & 76.1 & 7.5 & 14.9 & 1.5 & 53.9 & 13.2 & 26.3 & 6.5 \\
\hline I5 & 87.6 & 4.8 & 5.7 & 2.0 & 85.1. & 7.5 & & 30 & 89.6 & 4.5 & 4.5 & 1.5 & 88.2 & 2.6 & 7.9 & 1.3 \\
\hline I6 & 77.1 & 9.0 & 11.0 & 2.9 & 80.6 & 11.9 & & 3.0 & 79.1 & 6.0 & 13.4 & 1.5 & 72.4 & 9.2 & 14.5 & 3.9 \\
\hline I7 & 61.4 & 17.1 & 19.0 & 2.4 & 62.7 & 20.9 & 11.9 & 4.5 & 62.7 & 16.4 & 20.9 & 0 & 59.2 & 14.5 & 23.7 & 2.6 \\
\hline I8 & 29.5 & 32.9 & 34.4 & 7.9 & 47.8 & 26.9 & 22.4 & 3.0 & 19.4 & 38.8 & 38.8 & 3.0 & 22.4 & 32.9 & 40.8 & 3.9 \\
\hline I9 & 26.2 & 48.1 & 21.4 & 4.3 & 47,8 & 29.0 & 16.4 & 6.0 & 14.9 & 58.2 & 26.9 & 0 & 17.1 & 55.3 & 21.1 & 6.6 \\
\hline I10 & 45.7 & 23.3 & 25.2 & 5.7 & 493 & 28.4 & 17.9 & 4.5 & 52.2 & 20.9 & 22.4 & 4.5 & 36.8 & 21.1 & 34.2 & 7.9 \\
\hline I11 & 27.1 & 43.3 & 23.8 & 5. & $\widehat{20.9}$ & 62.7 & 11.9 & 4.5 & 28.4 & 37.3 & 29.9 & 4.5 & 31.6 & 31.6 & 28.9 & 7.9 \\
\hline I12 & 8.1 & 68.6 & 19.0 & 4.3 & 7.5 & 79.1 & 9.0 & 4.5 & 6.0 & 67.2 & 25.4 & 1.5 & 10.5 & 60.5 & 22.4 & 6.6 \\
\hline I13 & 17.1 & 48.6 & 29.0 & 5.2 & 14.9 & 62.7 & 17.9 & 4.5 & 17.9 & 55.2 & 26.9 & 0 & 18.4 & 30.3 & 40.8 & 10.5 \\
\hline
\end{tabular}

Table 2 - Frequency distribution for RAS Items: N=Nothing; al= a little; S=Something; $Q=Q u i t e ; A L=A$ Lot

\begin{tabular}{|c|c|c|c|c|c|c|c|c|c|c|c|c|c|c|c|c|c|c|c|c|}
\hline Item & \multicolumn{5}{|c|}{ ALL STUDENTS } & \multicolumn{5}{|c|}{ PRIMARY1 } & \multicolumn{5}{|c|}{ PRIM. 2} & \multicolumn{5}{|c|}{ SEC } \\
\hline & $\mathbf{N}$ & al & $\mathbf{S}$ & $\mathbf{Q}$ & $\mathbf{A L}$ & $\mathbf{N}$ & al & $\mathbf{S}$ & $\mathbf{Q}$ & $\mathbf{A L}$ & $\mathbf{N}$ & al & $\mathbf{S}$ & $\mathbf{Q}$ & $\mathbf{A L}$ & $\mathbf{N}$ & al & $\mathbf{S}$ & $\mathbf{Q}$ & $\mathbf{A L}$ \\
\hline I14 & 30.5 & 28.1 & 24.3 & 8.1 & 9.0 & 31.4 & 23.9 & 19.4 & 6.0 & 19.4 & 26.9 & 29.9 & 32.8 & 6.0 & 4.5 & 32.9 & 30.3 & 21.1 & 11.8 & 3.9 \\
\hline I15 & 54.8 & 20.0 & 11.0 & 6.2 & 8.1 & 56.7 & 11.9 & 9.0 & 4.5 & 17.9 & 55.2 & 22.4 & 14.9 & 3.0 & 4.5 & 52.6 & 25.0 & 9.2 & 10.5 & 2.6 \\
\hline I16 & 30.1 & 28.1 & 18.1 & 12.9 & 11.0 & 25.4 & 25.4 & 16.4 & 13.4 & 19.4 & 28.4 & 29.9 & 22.4 & 10.4 & 9.0 & 35.5 & 28.9 & 15.8 & 14.5 & 5.3 \\
\hline I17 & 29.6 & 19.0 & 19.0 & 17.1 & 15.2 & 37,3 & 11.9 & 7.5 & 13.4 & 29.9 & 26.9 & 11.9 & 26.9 & 22.4 & 11.9 & 25.0 & 31.6 & 22.4 & 15.8 & 5.3 \\
\hline I18 & 31.5 & 19.5 & 22.9 & 9.0 & 17.1 & 37,3 & 11.9 & 19.4 & 11.9 & 19.4 & 31.3 & 22.4 & 22.4 & 7.5 & 16.4 & 26.3 & 23.7 & 26.3 & 7.9 & 15.8 \\
\hline I19 & 18.1 & 13.3 & 17.6 & 27.1 & 23.8 & 29.9 & 10.4 & 6.0 & 16.4 & 37.3 & 13.4 & 16.4 & 17.9 & 31.3 & 20.9 & 10.5 & 13.2 & 27.6 & 32.9 & 14.5 \\
\hline $\mathrm{I} 20$ & 20.5 & 22.9 & 24.8 & 17.6 & 14.3 & 34.3 & 13.4 & 17.9 & 9.0 & 25.4 & 14.9 & 38.8 & 23.9 & 14.9 & 7.5 & 13.2 & 17.1 & 31.6 & 27.6 & 10.5 \\
\hline I21 & 27.1 & 22.4 & 22.4 & 10.0 & 18.1 & 23.9 & 16.4 & 14.9 & 14.9 & 29.9 & 25.4 & 22.4 & 29.9 & 6.0 & 16.4 & 31.6 & 27.6 & 22.4 & 9.2 & 9.2 \\
\hline I22 & 28.1 & 24.3 & 20.5 & 12.9 & 14.3 & 23.9 & 22.4 & 10.4 & 14.9 & 28.4 & 28.4 & 23.9 & 25.4 & 13.4 & 9.0 & 31.6 & 26.3 & 25.0 & 10.5 & 6.6 \\
\hline
\end{tabular}


Conde, M. Á., Fernández-Llamas, C., Rodríguez-Lera, F. J., Rodríguez-Sedano, F. J., Matellán-Olivera, V., \& García-Peñalvo, F. J. (2016). Analysing the attitude of students towards robots when lectured on programming by robotic or human teachers. In F. J. GarcíaPeñalvo (Ed.), Proceedings of the Fourth International Conference on Technological Ecosystems for Enhancing Multiculturality (TEEM'16) (Salamanca, Spain, November 2-4, 2016) (pp. 59-65). New York, NY, USA: ACM. doi: 10.1145/3012430.3012497

\begin{tabular}{|l|l|l|l|l|l|l|l|l|l|l|l|l|l|l|l|l|l|l|l|l|}
\hline I23 & 19.6 & 15.2 & 20.0 & 21.0 & 24.3 & 17.9 & 13.4 & 17.9 & 13.4 & 37.3 & 16.4 & 17.9 & 19.4 & 26.9 & 19.4 & 23.7 & 14.5 & 22.4 & 22.4 & 17.1 \\
\hline I24 & 25.3 & 20.5 & 19.0 & 13.3 & 21.9 & 22.4 & 19.4 & 17.9 & 11.9 & 28.4 & 25.4 & 14.9 & 23.9 & 14.9 & 20.9 & 27.6 & 26.3 & 15.8 & 23.2 & 17.1 \\
\hline
\end{tabular}

Table 3 shows the results of the statistical analysis of the NARS (Items 1-13) and RAS (Items 14-24) answers when comparing the human lectured group vs. the robot lectured one. Table shows the results of Levene test, Student T and Mann Whitney U test for NARS and RAS items. It also includes statistics about the number of students that interacts with the human teacher and with Baxter $\mathrm{Robot}\left(\mathrm{N}_{\mathrm{H}}\right.$ and $\left.\mathrm{N}_{\mathrm{B}}\right)$; the average value of the item for each group $\left(\bar{X}_{\mathrm{H}}\right.$ and $\left.\bar{X}_{\mathrm{B}}\right)$; the standard deviation $\left(\sigma_{\mathrm{H}}\right.$ and $\left.\sigma_{\mathrm{B}}\right)$; the contrast variable $(t)$ and the bilateral signification $(\rho)$ if Student's T test was applied or the Mann Whitney U signification $(\rho)$ if Levene signification is under 0.05 .

The values of Levene test signification are greater than 0.05 for all items except 12,14,15.

For the Student's T-test, a null hypothesis is posed, null hypothesis acceptance means that there are no significant differences between the groups. Null hypothesis is accepted if the bilateral significance of the exercise is greater than 0.05; otherwise, the null hypothesis is rejected. For the Mann Whitney $\bar{U}$ the Null hypothesis it Works in the same way.

Table 3 shows that there is a significant difference between groups for items 7,14 and 15. It is also interesting to note that there are differences between groups when taking into account their age range, so this methodology is applied per each age group.

In order to improve the readability of this paper in tables 4, 5 and 6 we are only showing the data for those items where there are significant differences between human-lectured groups, and robot lectured ones.

\section{DISCUSSION}

First, we are going to analyse the frequency of the answers taking into account all the students and dividing them in groups by the age range (as shown in Table 1). In order to organize the discussion, we have grouped NARS and RAS items according to Tsui et al [12].

NARS is divided as follows:

Table 3.- Results of the comparison of average values for the group that has a human teacher and the one that has Baxter.

\begin{tabular}{|l|l|l|l|l|l|l|l|l|l|l|}
\hline & Levene Sig & $\mathrm{N}_{\mathrm{H}}$ & $\mathrm{N}_{\mathrm{B}}$ & $\mathrm{X}_{\mathrm{H}}$ & $\sigma_{\mathrm{H}}$ & $\mathrm{X}_{\mathrm{B}}$ & $\sigma_{\mathrm{B}}$ & $t$ & $\bar{U}$ & $\rho$ \\
\hline Item 1 & 0.328 & 96 & 114 & 1.01 & 0.788 & 1.04 & 0.733 & -0.318 & - & 0.751 \\
\hline Item 2 & 0.408 & 96 & 114 & 0.60 & 0.852 & 0.75 & 0.935 & -1.168 & - & 0.244 \\
\hline Item 3 & 0.733 & 96 & 114 & 0.61 & 0.838 & 0.71 & 0.849 & -0.821 & - & 0.413 \\
\hline Item 4 & 0.735 & 96 & 114 & 0.47 & 0.794 & 0.44 & 0.828 & 0.241 & - & 0.810 \\
\hline Item 5 & 0.726 & 96 & 114 & 0.19 & 0.529 & 0.20 & 0.613 & 0.111 & - & 0.911 \\
\hline Item 6 & 0.412 & 96 & 114 & 0.36 & 0.796 & 0.42 & 0.797 & -0.512 & - & 0.609 \\
\hline Item 7 & 0.088 & 96 & 114 & 0.80 & 0.878 & 0.45 & 0.813 & 2.996 & - & 0.003 \\
\hline Item 8 & 0.186 & 96 & 114 & 0.07 & 0.824 & 1.13 & 0.901 & -0.497 & - & 0.620 \\
\hline Item 9 & 0.827 & 96 & 114 & 1.11 & 0.780 & 0.97 & 0.825 & 1.264 & - & 0.208 \\
\hline Item 10 & 0.593 & 96 & 114 & 0.93 & 0.976 & 0.89 & 0.963 & 0.342 & - & 0.810 \\
\hline Item 11 & 0.092 & 96 & 114 & 1.13 & 0.866 & 0.99 & 0.800 & 1.167 & & 0.244 \\
\hline Item 12 & 0.005 & 96 & 114 & 1.22 & 0.699 & 1.16 & 0.560 & & 5125.500 & 0.401 \\
\hline Item 13 & 0.094 & 96 & 114 & 1.19 & 0.850 & 1.25 & 0.738 & -0.610 & & 0.542 \\
\hline Item 14 & 0.002 & 96 & 114 & 1.69 & 1.361 & 1.11 & 1.079 & & 4127.000 & 0.002 \\
\hline Item 15 & 0.019 & 96 & 114 & 1.17 & 1.381 & 0.74 & 1.163 & & 4416.500 & 0.016 \\
\hline Item 16 & 0.391 & 96 & 114 & 1.61 & 1.370 & 1.39 & 1.292 & 1.171 & & 0.246 \\
\hline Item 17 & 0.857 & 96 & 114 & 1.81 & 1.446 & 1.63 & 1.428 & 0.911 & & 0.363 \\
\hline Item 18 & 0.184 & 96 & 114 & 1.66 & 1.381 & 1.58 & 1.499 & 0.419 & & 0.676 \\
\hline Item 19 & 0.524 & 96 & 114 & 2.20 & 1.388 & 2.34 & 1.437 & -0692 & & 0.490 \\
\hline Item 20 & 0.821 & 96 & 114 & 1.88 & 1.328 & 1.79 & 1.334 & 0.512 & & 0.609 \\
\hline Item 21 & 0.371 & 96 & 114 & 1.69 & 1.400 & 1.76 & 1.454 & -0.311 & & 0.756 \\
\hline Item 22 & 0.191 & 96 & 114 & 1.60 & 1.322 & 1.68 & 1.435 & -0.428 & & 0.669 \\
\hline Item 23 & 0.144 & 96 & 114 & 2.33 & 1.331 & 2.06 & 1.514 & 1.338 & & 0.182 \\
\hline Item 24 & 0.860 & 96 & 114 & 1.95 & 1.462 & 1.84 & 1.503 & 0.512 & & 0.609 \\
\hline
\end{tabular}


Conde, M. Á., Fernández-Llamas, C., Rodríguez-Lera, F. J., Rodríguez-Sedano, F. J., Matellán-Olivera, V., \& García-Peñalvo, F. J. (2016). Analysing the attitude of students towards robots when lectured on programming by robotic or human teachers. In F. J. GarcíaPeñalvo (Ed.), Proceedings of the Fourth International Conference on Technological Ecosystems for Enhancing Multiculturality (TEEM'16) (Salamanca, Spain, November 2-4, 2016) (pp. 59-65). New York, NY, USA: ACM. doi: 10.1145/3012430.3012497

- Interaction with the robot (NARS items 1 to 6). In this case most of the students feel comfortable interacting with robots. It should be noted that most of the students (with percentages between 87 and 89) assert they do not feel very nervous just standing in front of a robot, which gives an idea about or that do not feel paranoid talking with them. This shows that these students are used to interact with technology and although they had never interacted with a robot for them is not something stage. Moreover, it is also something to take into account that students from Secondary group have a significant lower percentage of "No" answers to the questions regarding with "I would hate the idea that robots can think". This can be explained because as they grew up and interact with technology they become aware about the problems that can be associated to a machine that could think.

- $\quad$ Social (NARS items 7 to 10). Results show that students are not especially worried about the future role of robots in our society or about how they would evolve. However, there are some differences when considering age groups, specially for items 8 and 10 . For Item 8 "Something bad might happen if robots developed into living beings", 47,8\% of younger students thought that there is not any problem with this, while the older ones showed a lower percentage between $19 \%$ and $22 \%$. We think that younger students could be still fascinating with technology and cannot understand any problem with this.

Regarding Item 10, "I feel that in the future society will be dominated by robots", majority of primary students (49 and $52 \%$ ) thinks this is not right, but only a $36 \%$ of the Secondary students answered this. This suggest that as they interact with technology, students are less sure about the future of technology in our society. Also sci-fi movies could have an impact on older students' answers.

- Emotions (NARS Items 11 to 13). This group is related to the opinion of the students about robots having got emotions. There is a significant difference specially for item 13, "I feel comforted being with robots that have emotions". As students got older percentages of "yes" answers decrease. This could be caused also, as in the previous group, by cultural influence (Sci-Fi).

RAS is divided as follows:

- Communication (RAS items 14 to 16). Students seem not to be worried about the behaviour of robots during a conversation, or if they are understanding what we are telling to them. There are no significant differences between groups of students of different ages.

Table 4. - Items with significant differences for Primary1. students

\begin{tabular}{|l|l|l|l|l|l|l|l|l|l|l|}
\hline & Levene Sig & $\mathrm{N}_{\mathrm{H}}$ & $\mathrm{N}_{\mathrm{B}}$ & $\mathrm{X}_{\mathrm{H}}$ & $\sigma_{\mathrm{H}}$ & $\mathrm{X}_{\mathrm{B}}$ & $\sigma_{\mathrm{B}}$ & $t$ & $\bar{U}$ & $\rho$ \\
\hline Item 14 & 0.003 & 29 & 38 & 2.46 & 1.503 & 0.97 & 1.102 & & 244.000 & 0.000 \\
\hline Item 15 & 0.019 & 29 & 38 & 1.64 & 1.726 & 0.82 & 1.373 & & 386.500 & 0.037 \\
\hline
\end{tabular}

Table 5. - Items with significant differences for PRIM 2 students

\begin{tabular}{|c|c|c|c|c|c|c|c|c|c|c|}
\hline & Levene Sig & $\mathrm{N}_{\mathrm{H}}$ & $\mathrm{N}_{\mathrm{B}}$ & $\mathrm{X}_{\mathrm{H}}$ & $\sigma_{\mathrm{H}}$ & $\mathrm{X}_{\mathrm{B}}$ & $\sigma_{\mathrm{B}}$ & $t$ & $\bar{U}$ & $\rho$ \\
\hline Item 2 & 0.351 & 34 & 33 & 0.41 & 0.743 & 0.82 & 0.882 & -2.041 & - & 0.045 \\
\hline & Levene Sig & $\overline{\mathrm{N}_{\mathrm{H}}}$ & $\mathrm{N}_{\mathrm{B}}$ & $\overline{X_{H}}$ & $\overline{\sigma_{\mathrm{H}}}$ & $\overline{X_{B}}$ & $\sigma_{\mathrm{B}}$ & $\bar{t}$ & $\bar{U}$ & $\rho$ \\
\hline Item 7 & 0.151 & 33 & 43 & 1.06 & 0.966 & 0.42 & 0.794 & 3.179 & - & 0.002 \\
\hline Item 15 & 0.161 & 33 & 43 & 1.15 & 1.253 & 0.63 & 0.976 & 2.048 & - & 0.044 \\
\hline
\end{tabular}

- $\quad$ Behaviour (RAS items 17 to 20). How robots move, the strong they are, or what they are going to do when you are interacting with them seems to worry younger students. This could be considered normal because they have less experience with technology than their older partners which could think that in controlled environments no harm would happen. This is shown by the percentages of their answers with "Nothing" or "A little".

- Discourse (RAS items 21 to 24). This group of questions is related to the way students interact with robots. The percentages of answers for this group are balanced in most ages, although it is possible to see that younger students are more worried about talking properly with robots than older ones. This can be explained because they have interacted less with technology in school and because they have less knowledge about the possible ways to talk with a robot.

Also this would be caused they are more interested in establishing real relationships with the robot, as shown by the percentage of answers "Yes" for the item12 of NARS ("If robots had emotions, I would be able to make friends with them"), that decreases as age increases.

The other question explored in this experiment was the evaluation of significant differences for each of NARS and RAS items between students that have a human teacher and those who have Baxter as a teacher. Results can be seen in tables 3, 4, 5 and 6. 
Conde, M. Á., Fernández-Llamas, C., Rodríguez-Lera, F. J., Rodríguez-Sedano, F. J., Matellán-Olivera, V., \& García-Peñalvo, F. J. (2016). Analysing the attitude of students towards robots when lectured on programming by robotic or human teachers. In F. J. GarcíaPeñalvo (Ed.), Proceedings of the Fourth International Conference on Technological Ecosystems for Enhancing Multiculturality (TEEM'16) (Salamanca, Spain, November 2-4, 2016) (pp. 59-65). New York, NY, USA: ACM. doi: 10.1145/3012430.3012497

From Table 3 it is possible to see three items with significant differences:

- Item 7. "I would feel uneasy if robots really had emotions". For this item Null hypothesis is rejected, which means that students that interact with the robot have different opinion about this from those who have not interacted with it. Students that interacted with Baxter gave answers with an average value of 0,40 which is close to "No", while those that interacted only with the human teacher gave an average value of 0,80 , closer to "Yes". This means that those that really made the experiment with the robot do not feel it as a threat.

- Item 14. Students lectured by the human teacher answered "Something" (average 1,69) to the question: "I would be worried if robots may talk about something irrelevant during conversation". But those in the Baxter group answer closer to "a little=1). This answer is consistent with previous one, that is, those who have interacted with the robot are less worried about the behaviour of the robot.

- Item 15. "I would be worried if robots cannot follow the stories of a conversation". For this item, the students in Baxter group gave an average answer of 0,74 (between "Nothing" $=0$ and "a little $=1$ " values), while students in the human-teacher group gave an average value of 1.17 (between "a little"=1 and "Something"=2). Once again, we think that this can be explained because those that interact with Baxter could see that conversations with Baxter are hard-coded to be social, while those in the humanteacher had not interacted with the robot at all and only can make assumptions based on their cultural.

In addition to the analysis of the differences between the robot-lectured and the human-lectured as whole, we have also made the comparison by age groups and the results were the following:

- Primary1 Group. Students of this age showed a significant difference for items 14 and 15 when comparing the human-lectured vs. the robot-lectured. These two items are related with the communication. We think that they are especially relevant for younger students, in fact the percentages are greater than the whole set of students. The Baxter group were less worried than the students in the human-teacher group.

- Primary 2 Group. For the students of this group there is a significant different for NARS item 2 "The word "robot" means nothing to me". With lower value for the students in the human-teacher group than for students in baxter group. It is strange that students do not know this word so, we think that the question was not properly understood.

- Secondary Group. In this case we do not observe significant differences. Only items 7 and 15 show a slightly difference. At this age, students have been more exposed to technology and they also understand better how robots work. We think that this could show that age is more relevant for the attitude towards robots than the exposition to them. This is an issue than we think that deserves further research to validate this intuition.

Finally, we would like to point out, that we made some changes to NARS and RAS questionnaires. Their questions have been translated into Spanish (from English although the original version was in Japanese) and have been slightly adapted, as suggested by other authors [13].

\section{CONCLUSION AND FURTHER WORK}

Regarding the first goal of the paper "Whether a robotic teacher does increase the NARS and RAS evaluation or not", we have found some differences (items 7, 14, and 15) that we attribute to the ignorance about how real robots work. When the students interact with a real robot, they are aware of their current limitations and their fears are alleviated.

The other goals of the paper are related to the factors that affect the perception of students towards robots. Several ones have been studied in the literature, many of them showing no relevance in the perception of the students towards robots. For instance, in [14] results showed low evaluations to robots as companions or teachers independently of the cultural origin (USA, Turkey and South Korea).

We have focused on age in this paper, and we can conclude that it is relevant according to the results discussed in previous section. But further experiments, more focused on age, have to be made to sustain this claim.

In particular, we would like to carry out other experiments using different robots (for instance humanoid as Nao) to study if its appearance, Nao is much smaller than Baxter, has any influence in students' perception. Another line of work that we envision is to use robots for longer interaction, trying to know if students' perception is changed in longer interactions as other studies in HRI have pointed out.

\section{ACKNOWLEDGMENTS}

The authors would like to thank the Spanish Ministry of Economy and Competitiveness for the partial support to this work by grant DPI2013-40534-R.

Authors want also to express their gratitude to Mr. Gonzalo Esteban, Mr. Ángel Manuel Guerrero, Mr. Jesús Balsa and Mr. Pablo Blanco for their assistance during the visit of the students.

\section{REFERENCES}

[1] Bers, M. U., Flannery, L., Kazakoff, E. R., \& Sullivan, A. (2014). Computational thinking and tinkering: Exploration of an early childhood robotics curriculum. Computers \& Education, 72, 145-157. 
Conde, M. Á., Fernández-Llamas, C., Rodríguez-Lera, F. J., Rodríguez-Sedano, F. J., Matellán-Olivera, V., \& García-Peñalvo, F. J. (2016). Analysing the attitude of students towards robots when lectured on programming by robotic or human teachers. In F. J. GarcíaPeñalvo (Ed.), Proceedings of the Fourth International Conference on Technological Ecosystems for Enhancing Multiculturality

(TEEM'16) (Salamanca, Spain, November 2-4, 2016) (pp. 59-65). New York, NY, USA: ACM. doi: 10.1145/3012430.3012497

[2] García-Peñalvo, F. J. (2016). What Computational Thinking Is. Journal of Information Technology Research, 9(3).

[3] García-Peñalvo, F. J. (2016). Proyecto TACCLE3 - Coding. In F. J. García-Peñalvo \& J. A. Mendes (Eds.), XVIII Simposio Internacional de Informática Educativa, SIIE 2016 (pp. 187-189). Salamanca, (Spain).

[4] Lee, I., Martin, F., Denner, J., Coulter, B., Allan, W., Erickson, J., Smith, J.M., and Werner, L. (2011). Computational thinking for youth in practice. ACM Inroads, 2(1), 32-37. DOI= $\underline{10.1145 / 1929887.1929902}$

[5] Salvini, P. Korsah, A. and Nourbaksh, I. (2016). Yet Another Robot Application? IEEE Robotics and Automation Magazine, 23(2), 74-80. DOI= $\underline{\text { 10.1109/MRA.2016.2550958 }}$

[6] Syrdal, D. S. Dautenhahn, K.Woods, S. Walters, M.L. and Koay K.L. (2006). Doing the right thing wrong' - Personality and tolerance to uncomfortable robot approaches, Proc. 15th IEEE International Workshop on Robot and Human Interactive Communication(RO-MAN), pp. 183-188. DOI= 10.1109/ROMAN.2006.314415

[7] Syrdal, D. S. Dautenhahn, K.Woods, S. Walters, M.L. and Koay K.L. (2007). Looking Good? Appearance Preferences and Robot Personality Inferences at Zero Acquaintance, Multidisciplinary Collaboration for Socially Assistive. Robotics: Papers from the AAAI Spring Symposium-Technical Report SS-07-07, pp. 86-92, 2007.

[8] Mutlu, B. Forlizzi, J. and Hodgins, J. (2006). A Storytelling Robot: Modeling and Evaluation of Human-like Gaze Behavior. IEEERAS International Conference on Humanoid Robots. DOI= 10.1109/ICHR.2006.321322

[9] Nomura, T. and Takagi, S. (2011), November. Exploring effects of educational backgrounds and gender in human-robot interaction. In 2011 International conference on user science and engineering $(i$-user $)$, pp. 24-29. DOI=10.1109/iUSEr.2011.6150530

[10] Nomura, T. Suzuki, T. Kanda, T. and Kato, K. (2006). Measurment of Negative Attitudes toward Robots. Interaction Studies, Vol. 7, no.3, pp. 437-454. DOI $=\underline{10.1075 / \text { is.7.3.14nom }}$

[11] Nomura, T. Kanda, T. Suzuki, T. and Kato, K. (2008). Prediction of Human Behavior in Human-Robot Interaction Using Psychological Scales for Anxiety and Negative Attitudes Toward Robots," IEEE Transactions on Robotics, vol. 24. pp. 442-451. DOI $=10.1109 /$ TRO.2007.914004

[12] Tsui, K.M. M. Desai, M., Yanco, H. A., Cramer, H., \& Kemper, N. (2010). Using the negative attitude toward robots scale with telepresence robots. In Proceedings of the 10th performance metrics for intelligent systems workshop (pp. 243-250). $\mathrm{DOI}=\underline{10.1145 / 2377576.2377621}$

[13] Serholt, S., and Barendregt, W. (2014). Students' attitudes towards the possible future of social robots in education. Workshop Proceedings of RO-MAN 2014.

[14] Lee, H. R., and Sabanović, S. (2014). Culturally variable preferences for robot design and use in South Korea, Turkey, and the United States. In Proceedings of the 2014 ACM/IEEE international conference on Human-robot interaction (pp. 17-24). DOI= $\underline{10.1145 / 2559636.2559676}$

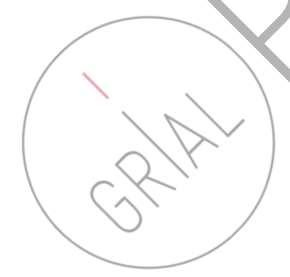

